\title{
Open Research Online
}

The Open University's repository of research publications and other research outputs

\section{Holism and understanding sustainability}

\section{Journal Item}

How to cite:

Bell, Simon and Morse, Stephen (2005). Holism and understanding sustainability. Systemic Practice and Action Research, 18(4) pp. 409-426.

For guidance on citations see $\underline{\text { FAQs }}$

(C) [not recorded]

Version: Accepted Manuscript

Link(s) to article on publisher's website:

http://dx.doi.org/doi:10.1007/s11213-005-7171-9

Copyright and Moral Rights for the articles on this site are retained by the individual authors and/or other copyright owners. For more information on Open Research Online's data policy on reuse of materials please consult the policies page.

\section{oro.open.ac.uk}


Systems Practice and Action Research, Vol 18, No. 4, August 2005

\title{
Holism, and Understanding Sustainability
}

Simon Bell and Stephen Morse ${ }^{1}$

1. Open Research Group, Systems Discipline, Open University.

2. Department of Geography, University of Reading

\begin{abstract}
In work undertaken in both Malta and Lebanon we have been reflecting on the current means by which the international community apply concepts intended to achieve what is called 'sustainable development'. In an attempt to make means and ends conform to each other we have developed an holistic approach to what is essentially a timeless need for understanding, systemic planning and compassionate stewardship. This essay indicates that we may be closer to holistic means with which to realise these goals than we know. It describes how some planning and analysis methods have their origins in ancient traditions. However, the milieu in which sustainability occurs is often unsympathetic to and sometimes incompatible with the ideals of holism.

The essay assesses the current understanding of sustainability and points to the need for a wider and more inclusive base to contemporary sustainability as practiced in the community.
\end{abstract}

\section{Sustainability as a contemporary equivalent of an ancient issue}

The concept of sustainability is now well established in contemporary vocabulary. Formally it has been conventionally defined as:

"Development that meets the needs of current generations without compromising the ability of future generations to meet their needs and aspirations."

WCED (1987)

Embedded within this definition we have the key element of equity; both for this and for the future generations. Websters dictionary defines it in more general terms as 'to uphold or support'.

It is a term however which is almost always associated with a purely secular worldview; predominantly that of the rich North of the world. Contradictions and opposition to this do exist (for example see the work of Paul Maiteny 2002) but overwhelmingly the intention behind sustainable endeavours refers specifically to environmental, social and economic needs and demands. While the birth and evolution of sustainable development has been the result of many influences including

\footnotetext{
${ }^{1}$ The authors wish to express their thanks to Jean-Paul Jeanrenaud of the World Wide Fund for Nature, Lou Wilson and Rachel Furze for their comments and contributions to this paper
} 
natural resource management, environmental philosophy and economics and questions that have arisen out of anthropology (such as the birth and death of civilizations), there is no doubt that it is the dominant paradigm with development today. Placing sustainable development between the often competing demands of Anthropo centric and Cosmo centric worldviews has produced a rich literature focused on the secular contest between the needs of both planet and humankind. What can best be described as an unholy management of expectations has arisen as competing demands of natural balance and human ambition have been compromised often to the mutual discontent of each group of proponents. This apparent duality of the needs of cosmos and humanity provides a model of opposites in conflict. How far should the pursuit of human well-being be allowed to influence decisions that have a negative impact on the cosmos? All too often this tension is resolved to the benefit of humans - a point easily illustrated from a consideration of the United Nation's Development Programme (UNDP) Human Development Report.

"the development process should meet the needs of the present generation without compromising the options of future generations. However, the concept of sustainable development is much broader than the protection of natural resources and the physical environment. It includes the protection of human lives in the future.

After all, it is people, not trees, whose future options need to be protected."

UNDP HDR (1990; pages 61-62)

The HDR is one of the prominent reports released each year on the state of global development, and ranks alongside such weighty offerings as the World Banks Development Reports. In essence this quotation summarises that quintessential problem with sustainability - the tendency for us to want to improve our lives in the place and space in which we live with a minimum of control.

A possible synthesis which points to issues operative at a deeper level of human experience and impinges on what can best be described as the spiritual needs of mankind is ignored or dealt with under a variety of inadequate titles variously defined as 'culture' or subsumed to corners of 'well being'. After all, such spiritual needs are not quantifiable and in the North we live in a society that increasingly wants targets and goals, with sanctions for those who fail to meet them. The notion that sustainable development can be perceived from a Theocentric worldview is relegated to the reports of special interest groups working on un-heralded projects for 'minority interests'. 


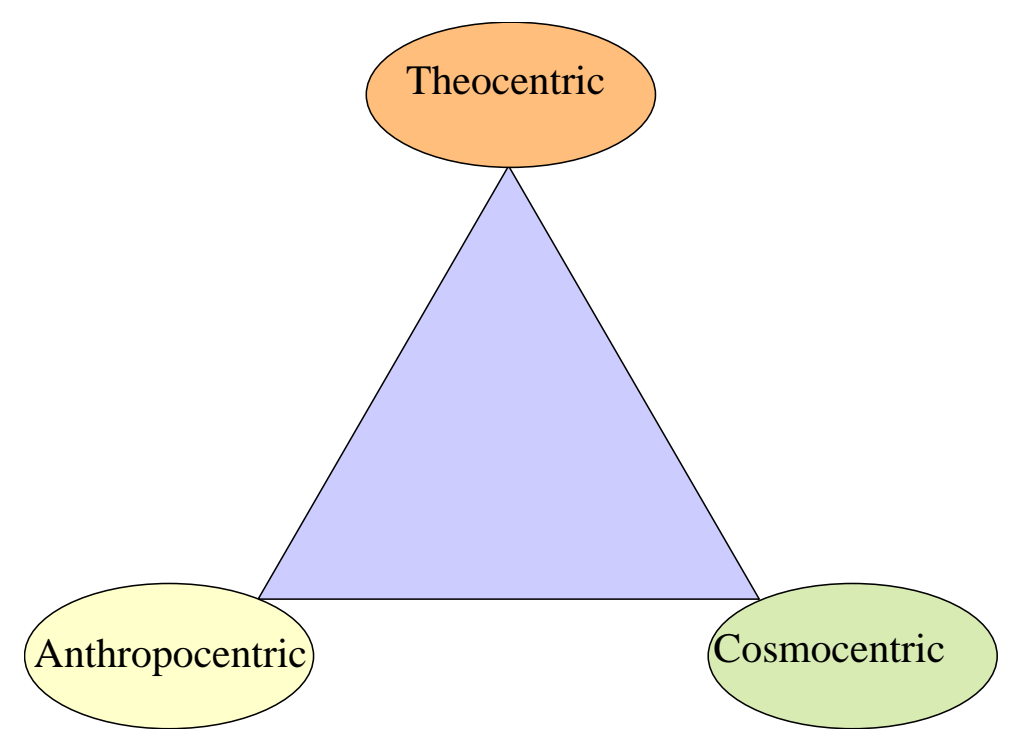

The notion of a trinity of worldviews at the root of any valuable work on sustainable development or the notion of combining Anthropocentric, Cosmocentric and Theocentric in one integral world view is seldom evident but it does have precedence. The notion of sustainability is not contemporary in flavour or in substance. Rather it relates back historically to a wide range of human endeavours and inspirations which can be traced back in the traditions of Europe, Asia, India, China and North America. Throughout them all runs a common, golden thread of wider inclusion and sensitivity to matters of an integral nature. Here are some brief examples:

Koran, an extract from The Imrans: 3:187 - 3:192

"God has sovereignty over the heavens and the earth. God has power over all things. In the creation of the heavens and the earth, and in the alternation of night and day, there are signs for men of sense; those that remember God when standing, sitting and lying down and reflecting on the creation of the heavens and the earth, saying: 'Lord, You have not created this in vain."

Extract from the Divine Pymander of Hermes Trismegistus

"Let all nature of the Cosmos receive the hearing of this hymn!

Be opened, O earth; let every deep of the abyss be opened for me.

Tremble not ye trees, for I would hymn unto the Lord of Creation, to the All and to the One.

Be opened ye heavens: stand still, ye winds: let the deathless sphere of God receive my words.

For I will sing praise unto Him who founded all, who fixed the earth, who suspended the heavens;

Extract from Lao Tse: The Simple Way,

Guarding the Small

While things are at rest, peace is easily maintained.

That which is foreseen is easily arranged for.

The feeble is easily broken: the minute is easily scattered. 
Prevent evil before it appear: secure order before disorder ensues.

A tree, which the arms cannot span, grew from the tiniest shoot.

A lofty tower was raised from a small mound of earth.

A journey of a thousand miles began with a single step/

He who makes unmakes,

He who grasps, lets go.

That is why the Master, by Wu Wei, can make, and by Wu Wei ${ }^{2}$ can unmake; by Wu Wei can grasp, and by Wu Wei let go.

Extract from "The Offering" by Teilhard de Chardin, Hymn to the Universe.

"Since once again, Lord - though this time not in the forests of the Aisne but in the steppes of Asia - I have neither bread, nor wine, nor altar, I will raise myself beyond these symbols, up to the pure majesty of the real itself; I, your priest, will make the whole earth my altar and on it will offer you all the labours and sufferings of the world."

Extract from a speech attributed to Chief Seattle

"Every part of this earth is sacred to my people.

Every sandy shore, every mist in the dark wood are holy in the memory and experience of my people.

We are part of the earth and it is part of us.

The perfumed flowers are our sisters; the bear, the deer, the great eagle - these are our brothers.

Each ghostly reflection in the clear water of the lakes tells of events and are memories in the life of my people.

The waters murmur is the voice of my father's father, the rivers are our brothers.

If we sell you our land remember that the air is precious to us.

That the air shares its spirit with all the life it supports.

The wind that gave our grandfather his first breath also receives his last sigh.

The earth does not belong to man, man belongs to the earth.

All things are connected.

Man did not weave the web of life, he is merely a strand.

Whatever he does to the web he does to himself."

Extract from a translation of the Adoration of RA when he rises in the Eastern Horizon of Heaven, Papyrus of Ani Chapter XV, by Normadi Ellis. Awakening Osiris.

"Stars fade like memory the instant before dawn. Low in the East, the sun appears golden as an opening eye. That which can be named must exist. That which is named can be written. That which is written can be remembered. That which is remembered lives. In the land of Egypt Osiris breathes. The sun rises and mists disperse. As I am, I was, and shall be, a thing of matter and heaven."

All of these traditions speak of a far richer vision of the world as an object worthy of sustaining. They speak of harmonies deeper and richer than those which appeal to more basic human appetites. They address humanity at a different level and provide coherent and lasting reasons for care. They go beyond human self-interest

\footnotetext{
${ }^{2} \mathrm{Wu}=$ the idea of non-action, Wei $=$ the idea of action.
} 
('enlightened' or not) and the ecological equilibrium of the cosmos. They address the fundamental issues of why we are, what we are and where we think we are going. These things in themselves provide us with, we would argue, a better grounding for sustainability in that they provide a higher point of thought with which to begin considering just what is meant by sustainability. Even for the worldly and the atheist they provide room for a deeper consideration of what it means to be human. It is perhaps surprising to think that those perhaps best placed to understand and appreciate the complexities of sustainability are those who have striven to understand the human spirit and how we have arrived at where we are today. After all our past was once someone's future. Seyyed Hossein Nasr (Nasr 1997) focuses the issue of crisis between man and cosmos down to the defining mind-set of our time and the consequences of its proliferation:

"In order for the modern sciences of nature to come into being, the substance of the cosmos had first to be emptied of its sacred character and become profane. The world view of modern science, especially as propagated through its vulgarization, itself contributed to this secularization of nature and of natural substances. The symbols in nature became facts, entities in themselves that are totally divorced from other orders of reality."

(Nasr 1997, page 21)

The core of our work and the underlying reason for this essay is in understanding the nexus of this crisis and in attempting to develop an integral understanding of sustainability without having this understanding neutered by the dominant, 'scientific' mind-set.

\section{Contradictions between the end - sustainability - and the means - the project.}

The community of policy makers, bureaucrats and practitioners have devised various means to perform the sustainability practice - to 'walk the talk'. It is in this context that we have been undertaking our own work. Our interest has been in developing the means to make sustainability of interest and value to populations where it is a critical issue. We wanted it to reflect their agendas and to embrace their concerns - whether human, environmental or spiritual. Also to give them the opportunity, if they wish to grasp it, to think about sustainability more widely and deeply. Too often it is seen as being the preserve of experts who 'know best.' The fact that this self-confessed 'superior' knowledge generates little or no interest in the wider community is irrelevant. The population as a whole elects to leave it with them. Thus sustainability is often left to so called experts and special interest groups and becomes the preserve of those who feel that they have the right to own the territory. We grew increasingly concerned with this tendency for sustainability to be seen from such limited worldviews and as the preserve of a self-chosen cadre, and somewhat surprised given that after all sustainability is 'life' and while most find contorted technical explanations and dictates boring there is an endless fascination with places and spaces and how people have coped both now and in history with the tensions that beset them. Look no further for evidence than the public's fascination with history and archaeology as expressed by prevalence in media programming and popular books. All of us want to know how we got here and are fascinated by the ways in which others live. Looking back at the tradition of the sustainability idea, we were 
concerned that the ethos of current procedures when linked to the dualist world view described above would inevitably lead to failure of the whole sustainability enterprise. The focus for all sustainability would be experts talking to experts about purely material issues, and not about all of us exploring our journey to and in the 'now', and how that journey will continue for our children to the future.

Our concern led us to develop an approach towards encouraging the inclusion of local people with local and diverse interests - very much in the spirit of the work of Ken Wilber:

"Any single perspective is likely to be partial, limited, perhaps even distorted, and only by taking multiple perspectives and multiple contexts can the knowledge quest be fruitfully advanced"

The Marriage of Sense and Soul, Ken Wilbur, page 124.

Wilber's comment should not be taken as gospel. Bits and pieces of information on the periphery, poorly integrated into one world view can distort more than they reveal. Inclusive and coherent methodology is essential. Our intention was to include ordinary people in the sustainability debate and not to provide unduly prescriptive tram-lines for that debate. We wanted to let them suggest the sustainability agenda free from the preconceived demarcations of experts and pressure groups. We were encouraged and supported in this work by the Mediterranean Blue Plan. ${ }^{3}$ Blue Plan is an organisation with a profound belief in the systemic nature of the world we experience. Describing themselves on their Web site they say:

"The image-rich term, "Plan Bleu" (Blue Plan) has several meanings :

1. A process of reflection on the Mediterranean region in all its vastness and complexity;

2. a research centre where this reflective process is carried out;

3. and the infrastructure of a non-profit organisation for management and operations.

Through its think-tank approach, the Blue Plan provides a package of data as well as systemic and prospective studies, combined in certain cases with proposals for action, which are intended to provide the Mediterranean countries with useful information for implementing sustainable socio-economic development that does not result in degradation of the environment"

www.planbleu.org

Blue Plan provided us with opportunities to develop our inclusive and participatory approach to sustainability analysis in sustainable development projects in Malta and in Lebanon. The details of our work are described elsewhere (Bell and Morse 1999; Bell and Morse 2002; Bell and Morse 2003; Bell and Morse 2003; Planbleu 2004). Within the limits of this paper it is not possible or necessary to discuss the full background to the work of the Mediterranean Action Plan (MAP) and the series of Coastal Area Management Programmes (CAMPs) which are undertaken by the range of agencies and organisations associated with MAP. Suffice to say for the sake of the coherence of this paper that the Blue Plan regional activity centre is located on the

\footnotetext{
${ }^{3}$ Blue Plan for the Mediterranean, 15 Rue Beethoven, F-06560 Valbonne Sophia Antipolis, France..
} 
French Riviera in Sophia-Antipolis, near Nice ${ }^{4}$. Blue Plan works in partnership with projects in the Mediterranean, encouraging certain activities and facilitating processes. It is not in a position to dictate to local agencies or to demand adherence to a top down policy. Blue plan has a tradition and focus on holistic forms of enquiry and systemic development of sustainability indicators.

At the time of the Malta CAMP there had already been several such projects in different parts of the Mediterranean including Greece, Tunisia and Egypt. Each CAMP has it's own focus and central issues of concern but the overriding issue of sustainability has been constant throughout. The main variation with the Malta CAMP project was the inclusion of our approach as the means selected to derive sustainable development indicators that had local meaning and value.

The Malta CAMP was focused on the North West of the island. Within this geographic area it was further organised into five thematic sub-projects, and three cross cutting sub-projects. The five thematic areas were:

1. Sustainable Coastal Management

2. Marine Conservation Areas

3. Integrated Water Resource Management

4. Erosion / Desertification Control Management

5. Tourism: impacts on health

An extract from the diary of one of the authors written at the outset of the project best describes the very personal level of their work:

"I think it is fair to say that inception workshops are not my favourite events. Past experience tells me that they are often political events and opportunities for much 'speechification' around the project aims and objectives. But here I was, making my way on an Air Malta flight - preparing myself for just such an event. On approaching Malta from the air for the first time (in daytime anyway) I was struck by the smallness of this densely populated island set in the wide blue of the Mediterranean sea. Actually, I was mistaken, my first impression was incorrect. The large woman in colourful clothes sitting next to me on the plane exclaimed to her friend 'Look, Gozo is beautiful today'. Gozo is Malta's small relation and partner in this mini archipelago set in the middle of tourist-haunted seas.

The plane lumbers heavily on and Gozo was behind us but in no time the flight had crossed the diminutive divide between this island and her partner. Malta itself was now in view. There is no doubt about it, the scale is best realised from a few hundred metres. From this height the academic can think objectively about his research, the consultant can assess the nature of problems and solutions and the island itself appears to be deceptively rural and of a relatively encouraging size to the 'fix it' mentality. But this is the north. In no time the ferry terminal to Gozo is behind us and the East-facing coast comes into view. This is an experience. From the beginnings of the urban sprawl which is the wealth and the agony of Malta which one first notices in Mellieha Bay, past Saint Paul's Bay, down to Pembroke and on to Sliema and Valletta itself, the impression of floating over a white and khaki, low built suburb is

\footnotetext{
${ }^{4}$ http://www.planbleu.org/indexa.htm
} 
inescapable. The extensive, low rise vista goes on and on interrupted only by occasional gold clad Church and warren roads. The plane edges inland, passing Mosta, Naxxar, splendid Mdina with the fortress citadel of the Knights of St John and Rabat as it makes its way to the destination of Luqa and final landing. But the firsttime visitor is not aware of the districts and villages, the fiercely individual minitowns and dormitories. All is one in a non-stop collage of residences and Mediterranean sprawl. The memory of the comparatively open spaces of Gozo and the north west of the island are now long gone although in reality only minutes have past. I could not help coming to the conclusion that if ever an island needed to consider its sustainable development surely this one did.

Malta has a population of approximately 380,000 on an island no bigger than the metropolitan area of a small city (approximately 246 square kilometres) - giving the amazingly high population density of around 1500 people per square kilometre. Gozo is tiny by comparison (65 square kilometres) and the very junior partner in the trinecoalition; Comino is almost invisible at 2.5 square kilometres. Malta is an independent republic and has been so since 1964 although there is a lingering British feel to the place which is emphasised by the charming English with Maltese dialect of sonorous lilt evident from the chatter of the lady who sits beside me on the plane, red public telephone boxes and the right hand drive cars.

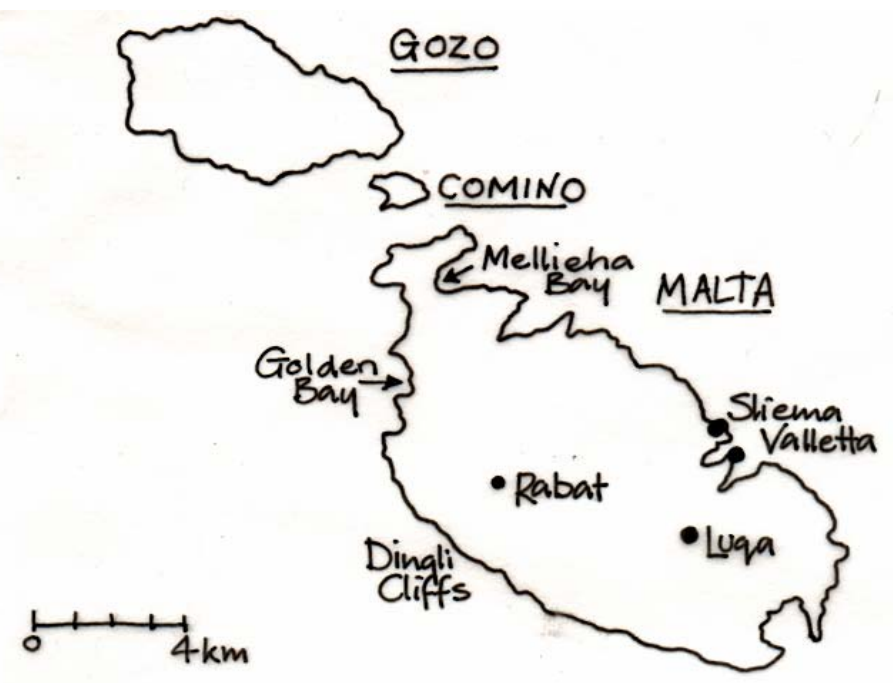

Map of Malta, Gozo and Comino

Descent into Luqa (our pilot was applauded by the Maltese on the flight - my colourful friend was ecstatic) hides the vista of unplanned suburban sprawl from view and leaves the first time visitor with the immediate worry of immigration (membership of the EU is still a nervous referendum away at the time of writing) followed by the teaming throng of the airport concourse. I am fortunate in not needing to queue for a taxi into Sliema where my hotel is located. I am met by a member of the Sustainability Indicators team and rapidly escorted to a car waiting in the darkening car park. 
Driving into the mass of joined up villages and towns I am again awed by the sheer weight of humanity that is the rich wealth of Malta. Buildings of all types surround the visitor as progress is made on perilous roads through a maze of poorly lit districts. But did I say that the island is small? Well it is but the journey to Sliema shows how deceptive some quick statistics can be. Fact must wait on perception for confirmation or denial. The journey is mind beguilingly complex. I like to keep a mental map of where I am in a country which I am visiting for the first time. I guess this springs from a career of working in some quite unruly places and the need to remember how I got in so I could get out again if I had to in a hurry! The darkling drive from Luqa to Sliema defeated my worn senses and soon had me lost in the flurry of turns and curves which makes five kilometres feel like fifty. Where am I in this confusion of architectural types and dimly lit roads?

My guide and driver is kindness made manifest. Polite and enquiring conversation goes on as the dark descends as evening gives way to night. I am asked about my preferences for the following day's workshop (room numbers, need for overhead projectors, etc), about the weather in England, about the state of the European Union and of course about the parlous state of English soccer - a topic which almost all male Maltese have a view on even if the teams of first choice are more likely to be found in the Italian Serie A than the dank turf of the super-rich clubs of the English Premiership. Old loyalties die hard and the immortal indicators of the league positions of Man $U$ and Chelsea hold an enduring appeal.

At last, after many a bump and jostle, we arrive at the hotel in Sliema where I am rapidly processed and, following kind rejoinders for a good repose, I leave my hosts and ascend to my globally familiar ' $L$ ' shaped hotel bedroom. A cold beer from the minibar and I am out on the smallest of balconies staring out over a dark landscape interrupted by lights upon lights only at last terminated by the brooding black of the sea and the sky. Warm breezes and sounds of laughter from the numerous cafes and restaurants which be-deck the Sliema promenade drift up to me on my rare (for Malta) vantage point on the sixth floor. One obvious point is I appear to be in one of the few multi-storey buildings on this most crowded island (a paradox I needed to wrestle with for some days). Feeling oddly exposed in my lofty eyrie, I retire for the night.

The days which have followed that first experience of Malta have led to many a rethink of what Malta is and how it got to its present situation. I can only write about Malta as I experience it, as I have been allowed to get to know its complexity and diversity. I do not claim privileged knowledge or a superior and scientific worldview. I express my limited understanding in the co-understanding that there are many more equally personal views about Malta which need to be held in mind and kept as a balance to the views I set out here. My work on the island has allowed me to travel with knowing and insightful guides and for this I am very grateful. This 'insider knowledge' has allowed me to see past some of the presenting outward appearances which Malta provides for the occasional visitor, the facade of the apparent to some of the struggles and anxieties which seem to lie behind every window in each household.

Let me begin with the north, well actually the west, for the north west are the subjects of this research and nothing is too far from anything else in Malta, even the cardinal points of the compass. On an early spring safari around the island I was taken with 
Italian and French colleagues from Sliema in the east, across the island via narrow and single carriage roads. There is almost no dual carriageway for Malta's 220,000 cars and as 10,000 new registrations are made each year, there is a potent challenge for those brave souls seeking parking at office hours. Our journey took us via Birkirkara and its magnificent church of St. Helen set amid a chaos of dwellings, and Rabat with the fortress of Mdina glowering over the open land. Our objective was the twee-sounding Dingli cliffs. A name which conjures up for me images of elves and goblins. I was being taken to the garden on Malta, the natural wonderland which lies outside the crushing urbanity of the east and the subject for the issues of sustainability which are at the core of the project which this note describes. It was early in the year but even so the flourish of spring was everywhere to be seen and smelt on the barren limestone landscape which is the terrain of the island. On approaching Dingli my attention was drawn to stonewall enclosed fields containing cages on posts. I enquired what they were and was told that they are traps set by the 'bird-trappers' (a lobby nearly as powerful in Malta as their north American cousins the National Rifle Association or NRA of the USA). It all seemed so unfair. Bird goes in cage, bird sings, wild bird comes, wild bird is caught, trapped or shot. Surely there is a better sport to play? Dingli itself is now in view. We get out of the car and head for the precipitous drop of the cliffs. This is one of the highest points of the island. These intimidating cliffs rear up from the Med. and then slope down to the heavy weight townscape of the Valetta conurbation which seems to weigh the eastern side of the island down to certain flood. Standing here the next conclusion I come to is that even the rural side of Malta appears urban. Limestone scenery can be unforgiving especially if it is sparsely mantled in green and criss-crossed by ruinous walls. In places an impression like the Burren, County Clare, in western Ireland is maintained, with small fields and green grass combining to form a likeable if harsh backdrop to sea and sky. But the eye soon wanders from this and other sadder sights jostle in. The walls are often ruined in aesthetic effect by fill in of brick, ugly block or appalling oil tank and rusty barbed wire. These stone walls have great value now for the cladding of fashionable homes in the up market districts around Sliema and Valletta and, as the young of the island turn their backs on the unprofitable labour of agriculture for the golden promises of tourist industry and casino, walls are surplus to requirement and can best be cashed in for once-only income. Too often the barren fields remain un-tilled now as agriculture looks harsh to the eyes seeking richer and easier pickings elsewhere - Malta like Ireland has always been generous in exporting her youth and talent. The jumble of broken, incomplete and ruinous walls form a home to the prickly pear plants which perform a covering job and mitigate against some of the scarring but a lasting impression of thoughtless and artless expediency is fostered. Turning towards the west, the eye scales down the cliff face to the narrow hinterland at the foot between cliff and sea. At first this is more pleasing. Some well-tended fields allow crops to flourish in the microclimate and a mix of field and tree hint at fertility and yields to come. But again other forces are at work. Here and there fields have been cleared and left barren. When asked their purpose I am told that these areas belong to the hunters and they are cleared in this way so as to appear a welcome landing site for migrating birds. The purpose of these grisly voids explained I wish I had not asked the purpose of the numerous hides set in fast growing eucalyptus trees. The trees make good hides but, dispersing over 70 gallons of water a day in transpiration from this arid, river-less island they represent a luxury which many think the hunters could do without. 
Driving on from west to north I am aware of some pleasant vistas and views over the small fields and rock walls of the northwest. past Malta's 'Great Wall', the Victoria Lines, natural faults built on originally by the Knights and then extended and developed by the British for defence in micro-imitation of its colossal cousin; past the diminutive resorts of the area at Ghajn Tuffieha and Golden Bay and up to Cirkewwa and the ferry crossing to tiny Gozo and tinier Comino. Passing Marfa point I take in the illegal development at Armier bay, where the planners came too late to stop wooden shacks becoming concrete single story dwellings, second homes and boat houses to those with the courage to bet on theft going unpunished because of political inertia.

I begin to get the point. This is not empty and unspoilt countryside, the north west is not a rural idyll tremulously positioned on the edge of developer oblivion but this is space and hope and not-urban and the best which Malta has left to sustain. What is done is done and there is no clawing back the fields from the rampant block and cement of the east and south (have I mentioned the south?) but, before the island succumbs to 100\% coverage, there is a small time for an in-take of breath, for some planning and thinking and valuing what is left of the countryside. And this time for thinking can be assisted by information about the scale of the problem and the rate of loss. What does the loss mean to Malta? As I said at the beginning of this entry, if anywhere on earth deserves a conversation with itself regarding the meaning and doing of sustainable development then surely Malta does?

At last the purpose of the visits that I was to make over the coming years and the point of the work which Steve and I were to engage in dawned on me. Here was a vital and urgent need; a need for understanding, communication and desperate dialogue. Colloquy more on a religious footing than an objective appraisal of monetary value is prayed for from the landscape of an island which has sold it's soul for other people's holiday days. Malta has reaped as it has sown and the cracks in the fields are becoming fissures to match the rill erosion evident in so much of the un-tilled landscape. With an embryonic planning authority trying to make itself heard over the multitudinous voices of developers (legal and illegal) this is going to be a close run thing. I no longer have a methodology to be tested and tried in an academically interesting context divorced of any emotion or subjectivity. I have a local difficulty on a national scale to scan, accept, communicate, invite others to consider and hope for. I am already lost as the objective academic looking down the microscope at the victims of my study. I have landed, the context of my study rises up around me like the suburbia of Luqa when I first arrived and already I care about the outcome. This is no exercise in a scientific sustainability analysis to form the stuff of learned papers - it is a struggle against time to understand desperate complexity in communion with friends" (Bell and Morse 2003 b pages 61 - 65).

These are the early reflections of one of the authors. During the process of our work, first in Malta and later in the Lebanon we engaged local communities in discussions about their vision of their locality and developed conversations about what sustainability meant to them. We encouraged them to develop indicators which they thought were meaningful in measuring what they thought was important in terms of sustainability. We developed the means to measure the indicators and discussed how best this information might be used by policy makers to assist with the on-going 
sustainable development of the regions involved. Although our progress towards an integral world view was modest and the focus for the indicators tended to be directed towards ecology versus economy, we gained some considerable enthusiasm for the process - as witnessed by this stakeholder in Malta:

The workshop sessions and the direct hands on experience in understanding the various stages of the process has been the success of this project, particularly since groups would involve themselves in systemic discussions analysing the issues from different perspectives to come up with a collectively acceptable approach. All teams were unanimous on this. (Comments from a member of the SPSA core team). (Bell and Morse 2003 b. page 118)

However an overarching observation came to light from our practice. Despite the best intentions of ourselves and Blue Plan, our sustainability 'walk' was constrained by the project process itself. Short term and results driven, the medium in which the sustainability practice was being undertaken was not entirely conducive to the sustainability outcome we were seeking. We labelled this medium the 'projectified world order' - in other words the compartmentalised world - and will say more about this shortly. An entry from one of the author's diaries is instructive:

"It is frustrating how the emphasis continues to be on the 'end product' - the 'deliverable' - the list of indicators. We discuss amongst ourselves how this misses what the participants themselves see as important - the opportunity to discuss what sustainability means to them and how it could be achieved. Yet this deeper learning does not really find a place in the analysis. All that seems to be important is whether the process 'works' in delivering the indicators!'

Our intention had not been to revolutionise or aggressively challenge existing processes: we sought only to undertake our work based on inclusion and participation in defining sustainability from an integral viewpoint. The fact that this appeared at times to be undermined by the system in which we were operating provided us with a conundrum.

The observed tendency within projects of all kinds is for practitioners like ourselves to get on with our work and 'make do'.. Rarely do things go smoothly or to plan; our job is to 'muddle through'. With this approach in mind, the project is planned and undertaken, people of good intent are busy, money is spent and outcomes are published. The research papers follow and the partial or complete success or failure of sustainability work goes up on the shelves. Few insiders question the system which is largely responsible for producing the result.

On reflection our opinion was that well intentioned people working with sympathetic colleagues on sustainability projects would be likely to achieve less than they might in their undertaking as a consequence of the project frame of mind - the compartmentalised world order. 


\section{Underlying traditions behind the babble}

It is our contention that the milieu in which projects working on sustainability operate is often antagonistic. It is antagonistic in terms of the limited timescale allowed for what should be activities for the long term (some might argue 'outside time'), the project approach and the language and practice of exclusion. Approach and language can be mitigated against but the dominant process of dividing up human activity into bite sized, costed and evaluated chunks is deeply inimical to long term sustainability. If the unit of measure is one or two or three years then, by definition, little or nothing sustainable can be known to have been achieved. Sustainability needs to be set in an enduring process if it is to make sense. Also, how many of us are enthused by 'projects' typically setup by someone 'out there' with little consultation with those it is meant to engage with? How many of us know that we are part of a sustainable development project at the moment being enacted either at international, national or local levels? How many individuals in the UK for example realise that their local authority has a sustainable development project in force as we write this article (the Local Agenda 21 programme following the 1992 Earth Summit in Rio de Janeiro)? Perhaps most telling, how many care? Another extract from the diary of one of the authors helps to illustrate the point:

"I discuss with a colleague at a sustainable development conference who is clearly upset about one of the papers which highlights a lack of public awareness regarding sustainability. How can they not know or care he laments? I point out that people do care about education, health and the cleanliness of the streets in which they live - and these issues are very much part of sustainability. People do care about and are aware of sustainability - they just don't know the label. But does the label matter?”

Despite the problems of the milieu, as we continued with our work we became aware that the processes we engaged with in the course of the project had more to do with the deeper human tradition from which we argue contemporary sustainability arose than we had at first realised.

Our main methodology ${ }^{5}$ is called SPSA - Systemic and Prospective Sustainability Analysis. It is not our intention to go into detail about this here but a cursory glance at Figure 1 will provide the evidence that SPSA in form and intention implies an unending process - a process more akin to the worldview of Chief Seattle and Lao Tse than the organisers of the compartmentalised world order.

\footnotetext{
${ }^{5}$ Developed in collaboration with Blue Plan
} 
Figure 1 - Timeless sustainability process .

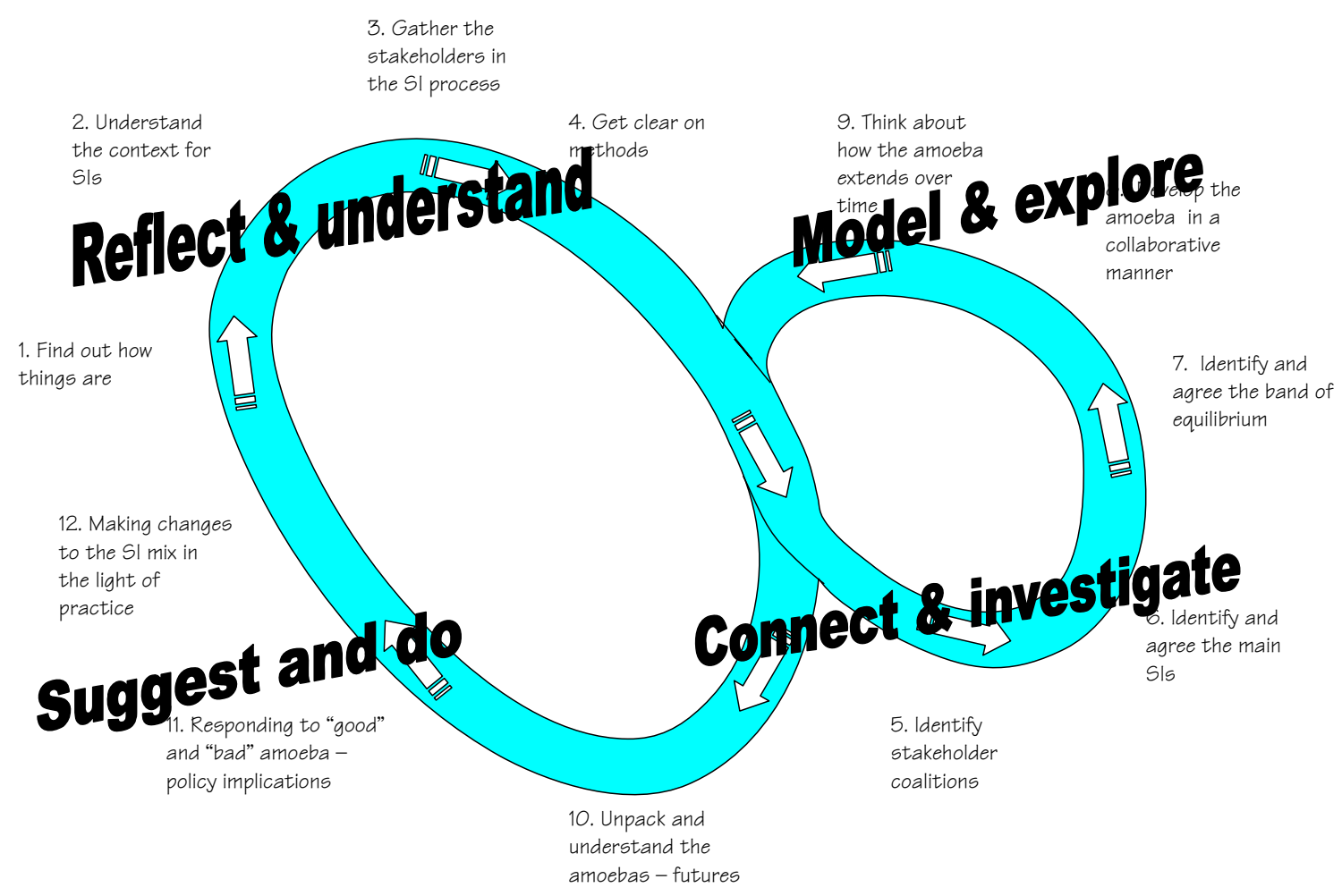

Within our main methodology we make use of a number of sub-methods and alternative means to problem solve and arrive at measures of sustainability. In reviewing these it became apparent again that the legacy of the ancient wisdom still underpins these contemporary devices. Our main operating method for the diagnosis of sustainability issues is called Soft Systems Methodology (Checkland 1981) (SSM). This methodology, like so many contemporary devices for problem solving effectively deals with three questions: what is?, what may be? and how do we get there? The questions are not immediately obvious or apparent but nevertheless they constitute the substantive meaning for the methodology. It is our contention that SSM conforms to the spirit of the $35^{\text {th }}$ Precept of Proclus from the $5^{\text {th }}$ Century AD abiding, proceeding and returning. The precept is both integral in terms of itself and allows for the inclusion of human, cosmic and spiritual interests within a process that is essentially predicated on learning about ourselves. The Precept denies the potential for disunion:

Every thing caused, abides in, proceeds from, an, returns, or is converted to, its cause. For if it alone abided, it would in no respect differ from its cause, being without separation and distinction in term. .. But if it alone proceeded, it would be unconjoined and deprived of sympathy with its cause... And if it were alone converted, how can that which has not its essence from the cause, be essentially converted to that which is foreign to its nature? (Taylor 1994) 
In this extract Proclus both defines the trine process of causality to the outermost of its effects and links the process to the three stages. We argue that this logic demonstrably underpins rational problem solving processes (and many others) to the present day. The supplementary approach which we used for organizing our aspect of the sustainability projects - the Logical Frameworks Approach or LFA - works on a four level causality which conforms exactly to Aristotle's observation in the Metaphysics. These four levels of causality deal with all levels of intellectual effort from that dealing with concrete matters to the attainment of noetic insight. In a previous publication one of the authors set out this discovery as follows:

"I was describing the LFA to a philosopher friend and he spotted it immediately! He told me to read Aristotle. Aristotle described a doctrine of 'Four causes' by which it has been argued (Flew 1979) that he meant that there were four fundamental types of question that could be asked of any specific issue or problem (or for our purposes here, project). The four types of questions form a hierarchy - from bottom to top - the material, the formal, the efficient and the final. Aristotle describes these in 'The Metaphysics' as related to the making of a statue (a project certainly). Material questions would relate to: 'what is the statue made of?' (answers might include, for example, bronze and labour). Formal questions would ask: 'what the bronze statue is supposed to be?' (for example a statue of the Leader of the Gods, Zeus). Efficient questions might relate to: 'what the statue was expected to be for?' (for example,e as an object of reverence) and the final question might relate to: "why was the statue made at all?' (for example to assist in maintaining the moral and ethical structure of the state).

Making statues, making rural development policy, building up health infrastructure the thinking can be thought of as being similar at one level anyway. Considering the LFA in this light the logic behind the LFA can be argued to work as follows:

- Material questions can be interpreted as relating to the physical processes and activities involved in any process.

- Formal questions relate to what the activities when brought together produce as output.

- Efficient questions are to do with what the produced thing will be.

- Final questions are interested in how this thing contributes to wider needs and purposes.

Intentionally or unintentionally these questions arise in the development and evaluation of LogFrames as they are often presented. Further, these four levels of questioning have provided me with what I consider to be an holistic set of questions to ask of any project context." (Bell 2000)

Neither Aristotle or Proclus limited their understanding of causality to the human and the natural. They allowed for deeper and more spiritual driving forces for the world around us which include contemporary concerns but also transcend them. Furthermore, perhaps the underlying basis of both SSM and LFA demonstrate the old adage that in terms of human thought there is nothing new under the sun.

In our use of SPSA, SSM and LFA we have found a correspondence with contemporary thinking relating unconsciously to inclusive systemic and holistic rubrics which recognize the need for more rounded understandings of sustainability and providing for the Theo centric as well as the human and the natural. Our contention is that for sustainable development to really mean something we all 
(specialists and local communities alike) need to 'walk the walk' together with a growing appreciation that this is a contemporary expression of an age old concern of relating humanity to cosmos and Divinity. We need to consider how these issues impinge on each other and on our world experience. It seems that the substratum of thinking behind the approaches we make use of today are of ancient origin and are consistent with the ethos of an holistic approach. However the medium in which they are employed - through the compartmentalized world order - remains largely at variance with them.

\section{The potential for something better - stewardship and partnership}

Our work has led us to explore the potential for a meaningful engagement with sustainability projects. We do not wish to present colleagues, agencies and organisations involved in such work as either wicked or incompetent.

Sustainability has arisen at this time as a key issue and it is still finding its place in the ever-changing list of human priorities. It is a relative new-comer and as such its value is attested to and examined in practice. It will organise itself and be organised by protagonists and antagonists. Our concern is that in this process the conventional, secular and excluding frame of mind of both protagonist and antagonist will neuter the potential for sustainability to achieve what could be achieved.

In this spirit we do not see sustainability as the issue: rather it is the dominant belief and secular obsession which underlie project processes. This belief, epitomised as the compartmentalised world order, is the shadow under which sustainability processes and initiatives grow up. This limits their scope and reduces their capacity. At an empirical level it reduces participation, inclusion and quality to quantity. As S. H. Nasr argues:

"The quantitative character of modern science must be pointed out in particular because it exists as a general tendency which seeks as an ideal the reduction of all quality to quantity and all that is essential in the metaphysical sense to the material" (Nasr 1997 page 21)

At an abstract and spiritual level the compartmentalised world order superimposes Anthropocentric and Cosmocentric duality and conflict as obligatory and inescapable. Our concern is to provide contexts in which sustainability can flourish timelessly and freely, providing room for humanity to consider itself, the cosmos and innate spirituality (by whatever means this is designated) in an integral worldview. To this end we would suggest that the following elaborations to project processes might provide a beginning:

1. Inclusion of local communities in the decision making at the inception of projects for sustainable development

2. Inclusion of long-term objectives and goals at the initiation of the project

3. A requirement of all sustainable development project donors to seek long-term funding for project processes - beyond the run of the project

4. Inclusion of spiritual, ethical and cultural concerns and needs in definitions of sustainable outcomes 
5. Valuing qualitative as well as quantitative issues

Such an open and inclusive process would provide the opportunity for wider partnerships and the real outworking of the rigours and responsibilities of human stewardship which should be sustained. Bite sized and piecemeal approaches can never provide an adequate medium for such engagement.

However, all these five points are likely to encounter resistance amongst those wedded to the project frame of mind. Including local communities means sharing power and long-term thinking is anathema to those whose traditional time-boundaries are but a year or two. What is needed is a methodical device that is compatible with project thinking but at the same time encourages the adoption of these points.

“We discuss the 'problem with projects' time and time again, but it's not easy to see a way forward. While some writers appear to reject the project paraphernalia as a vehicle for achieving sustainability we can see no alternative given the dominance of the project approach. But how to make project people more aware of their limitations in a sustainability context? Maybe we could emphasise the value of learning and the process of Learning Cycles, reflecting on what is being done in the project and assessing it for its value before going on to the next phase of project activity, and then reflecting again. Long discussions about valuing these kinds of learning cycles could form the basis of a structured framework to raise awareness of the learning experience within sustainability projects. Maybe that is one way forward?"

\section{Conclusions}

This essay, working from practical experience, has attempted to review such experiences in terms of wider and deeper worldviews. The authors strongly advocate an integral worldview, encompassing wider concerns. If sustainability is to be more than a label for a platitude it needs to be undertaken in a medium which is commensurate with its true identity and in a manner whereby its widest potential can be realised.

\section{References}

Bell, S. (2000). "Logical Frameworks, Aristotle and Soft Systems: A note on the origins, values and uses of Logical Frameworks." Public Administration and Development 20(1): 29-31.

Bell, S. and S. Morse (1999). Sustainability Indicators: Measuring the immeasurable. London, Earthscan.

Bell, S. and S. Morse (2002). Experiences with Sustainability Indicators and

Stakeholder Participation: a case study relating to a 'Blue Plan' project in Malta. The 2002 International Sustainable Development Research, University of Manchester, ERP Environment.

Bell, S. and S. Morse (2003). Learning from Experience in Sustainability. The 2003 International Sustainable Development Research Conference, University of Nottingham, UK. 
Bell, S. and S. Morse (2003). Measuring Sustainability: Learning from Doing. London, Earthscan.

Checkland, P. B. (1981). Systems thinking, Systems Practise. Chichester, Wiley. Flew, A. (1979). A Dictionary of Philosophy. London, Pan.

Maiteny, P. (2002). Values, Spirituality and Education for Sustainable Development. UNED UK Conference on Education for Sustainable Development, London, UNED Forum.

Nasr, H. S. (1997). Man and Nature: The Spiritual Crisis in Modern Man. Chicago, ABC International Group Inc.

Planbleu (2004). http://www.planbleu.org/indexa.htm. Sophia Antipolis.

Taylor, T. (1994). Proclus' Elements of Theology. Chippenham, The Prometheus Trust.

United Nations Development Programme (UNDP) (1990). The Human Development Report. Concept and measurement of human development. UNDP, New York.

World Commission for Environment and Development (WCED) (1987) Our Common Future, Oxford University Press, Oxford 